\title{
Optimal Control of Brushless DC Motor for Electric Vehicle Based on Particle Swarm Optimization
}

\author{
Ali Hadi Abdulwahid \\ Department of Electrical Power Engineering, Southern Technical University, Basra, Iraq
}

\begin{abstract}
The revolution of electric vehicles is characterized by rapid development. This type of vehicle has witnessed its greatest growth; the reason for interest in electric vehicles is not only in reducing dependence on oil but also in preserving the environment. The Brushless DC (BLDC) plays a decisive role in electric vehicles and has gradually replaced the DC motor in many applications as it has no brush and commutator erosion and has many advantages including high efficiency, reliability and smaller size, less weight, need-less maintenance, long operating life and absence of ionized sparks due to the commutator. In this study, the Optimization algorithm for Particle Swarm (PSO) was used to find the optimal parameters of the PID. The main goal of this study is to get a stable, reliable and controlled system, the results of the simulation show a significant increase in the performance of the BLDC motor compared to the existing methods. To be a more effective way to control the position, torque, speed.
\end{abstract}

Key words: Optimal control, particle swarm optimization, PID controller, brushless DC motor, DC (BLDC), parameters

\section{INTRODUCTION}

The BLDC engine is simple in structure and more economical than other engines. BLDCs are widely used in many industrial applications and vehicles. Due to high efficiency, long life, high dynamic performance and high speed compared to torque characteristics, the proposed method is used to provide better system performance with minimal errors. The main task is to use the technical optimization of the particle swarm to adjust the parameters of a Proportional Integral Derivative controller (PID) to improve its performance (Zhang and Wang, 2016; Da Cunha Reis et al., 2015; Ou and Lin, 2006).

The PSO request to the controller provides the ability to tune to a procedure continuously as well as the request of the optimization algorithm to the PID controller allows it to provide an optimal result by searching for the best set of solutions for the PID parameters (Nasri et al., 2007; Viji and Arumugam, 2017).

Due to its advantages which make it useful where space and weight are critical factors. In addition, the necessary position information can be obtained through the hall sensors, to offer a higher torque, distribution of the winding the torque of a DC brushless motor depends on the reverse electrical potential of a certain location. The BLDC motor generally has a trapezoidal shape of the rear EMF signal and the stator consists of a normal rectangular stator feed, provided it has a stable torque (Kamalapathi et al., 2017; Ibrahim et al., 2014; Chen and Kuo, 2017; Kim et al., 2007; Rajkumar et al., 2017).

A permanent magnet $\mathrm{DC}$ motor uses a mechanical commutator and an electric brush for commutation whereas the BLDC motor uses hall effect sensors. In the stator of the BLDC motor, the coils and rotors are the permanent magnet. The stator generates a magnetic field to rotate the rotor. The hall effect sensor determines the position of the rotor as a reversing signal (Das et al., 2017; Gowthaman et al., 2017; Kumar et al., 2017).

Therefore, the BLDC motor uses a permanent magnet instead of a coil in the armature and does not require a brush. In this study, a 3-phase and half-bridge pulse width modulator controls the speed of the motor. Equation 1-5 of the motor's characteristics can be expressed as Kavitha et al. (2017) and Singh et al. (2018):

$$
\begin{gathered}
v_{\mathrm{app}}(\mathrm{t})=\mathrm{L} \frac{\mathrm{di}(\mathrm{t})}{\mathrm{dt}}+\mathrm{R} \cdot \mathrm{i}(\mathrm{t})+v_{\mathrm{emf}}(\mathrm{t}) \\
v_{\mathrm{emf}}(\mathrm{t})=\mathrm{K}_{\mathrm{b}} \cdot \omega(\mathrm{t})
\end{gathered}
$$




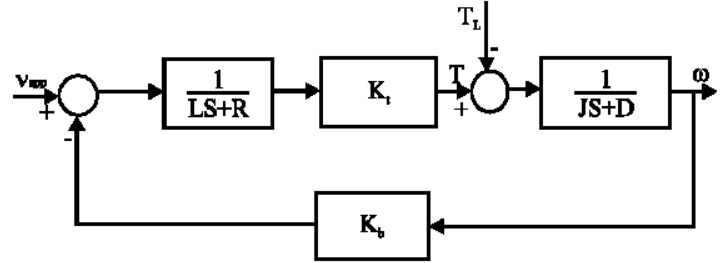

Fig. 1: Block diagram of BLDC motor

$$
\begin{gathered}
T(t)=K_{t} \cdot i(t) \\
T(t)=J \frac{d \omega(t)}{d t}+D \cdot \omega(t) \\
\frac{w(s)}{v_{\text {app }}}=\frac{K_{t}}{L J \cdot S^{2}+(L D+R J) S+K_{t} K_{b}}
\end{gathered}
$$

Where:

$$
\begin{aligned}
& v_{\text {app }}(\mathrm{t})=\text { The applied voltage } \\
& \omega(\mathrm{t}) \mathrm{t}=\text { The motor speed } \\
& \mathrm{L}=\text { The inductance of the stator } \\
& \mathrm{i}(\mathrm{t})=\text { The circuit current } \\
& \mathrm{R}=\text { The stator resistance } \\
& v_{\text {enf }}(t) t=\text { The inverse electromotive force } \\
& \mathrm{T}=\text { The Torque engine } \\
& \mathrm{D}=\text { The viscous coefficient } \\
& \mathrm{J}=\text { The moment of inertia } \\
& \mathrm{K}_{\mathrm{t}}=\text { The constant of engine torque and } \mathrm{K}_{\mathrm{b}} \text { is the } \\
& \text { constant electromotive force }
\end{aligned}
$$

In this study, the BLDC motor is driven by the PWM and controlled by the voltage of the source inverter. The motor stator voltage is adjusted to control the speed of the BLDC motor. Figure 1 shows a block diagram of a BLDC motor.

\section{MATERIALS AND METHODS}

Conventional PI controller: In order to meet the specification of performance requirements (Traditional control design), the performance of the control system is usually measured by taking the step function as a control point variable and then measuring the response process variable. The response is usually measured by measuring the properties of a particular waveform. And then measuring the time the system needs to go from $10-90 \%$ of its value in a stable or final state.

A surveillance system should be developed that works satisfactorily in the worst case. The ability of a control system to overcome the effects of interference can be measured by the control system rejecting interference. Once the performance requirements have been determined, the system should be studied and the appropriate control system selected.

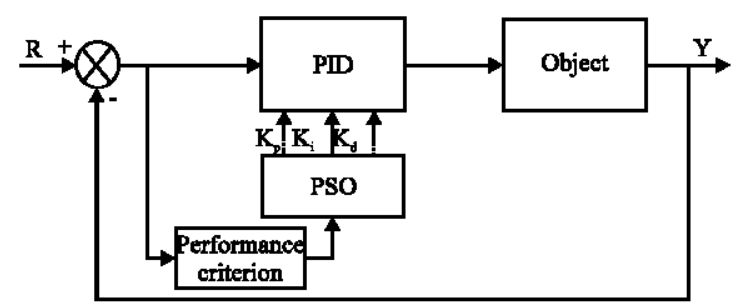

Fig. 2: Optimal design of the PID control

$\mathrm{PD}$ controllers are well known because they are easy to use. It is also characterized by being the simplest method of control and widely used in the industry. A control system malfunctions and becomes unstable when incorrect adjustment and control values are used. PIDs show weak control characteristics with a long delay for modern applications it have non-linear effects. Therefore, the parameters of the controller should be adjusted appropriately for the proper functioning of the control (Robinson and Rahmat-Samii, 2004).

PSO algorithm: The algorithm of PSO has been used to obtain the control unit optimal. These particles are randomly initialized and pass through the multidimensional space. During the flight, these particles updated its velocity and position based on its own experience (Fig. 2).

The upgrade procedure moves the particle swarm towards a region with a good fitness function and each particle clusters around the point with the best fitness function. In the $\mathrm{PSO}$, each particle contains 3 conditions, $\mathrm{K}_{\mathrm{p}}, \mathrm{K}_{\mathrm{i}}$ and $\mathrm{K}_{\mathrm{d}}$. The PSO is mainly simulating models of birds in a 3-dimensional space. Each agent position is represented by the $\mathrm{XYZ}$ axis and the VX, VY and VZ velocity (which represent a speed towards the $x$-z-axis). The location of the agent is changed by the speed and location of the information. Each agent is known (pbest) and its position is XYZ. This information is an analogy of each agent's personal experience. In addition, each agent knows best (gbest) among the pbests. This information is the analogy of the knowledge about how the other agents perform.

\footnotetext{
Algorithm; PSO algorithm:

1: Create a "population" of agents (particles) that is evenly distributed in $\mathrm{X}$

2: Evaluate each particle position according to the objective function

3: If the position of the particles is better than before it is updated

4: Based on the best mode of the previous particle (the best particle is determined)

5: The speed of the particle is updated: Eq. 6

6: Transfer the particles to their new locations: Eq. 8

7: Go to step 2 until the stop criteria are met
} 
Here, the absolute error of integration is the used for fitness and should be minimized to improve performance. This can be done by modifying the concept of speed. You can adjust the speed of each factor by the following Eq. 6 :

$$
\begin{aligned}
& v_{\mathrm{i}}^{\mathrm{k}+1}=\mathrm{w}+v_{\mathrm{i}}^{\mathrm{k}}+\mathrm{C}_{1} \text { rand }_{1} \times\left(\text { pdest }_{\mathrm{i}}-\mathrm{s}_{\mathrm{i}}^{\mathrm{k}}\right)+ \\
& \mathrm{C}_{2} \text { } \text { and }_{2} \times\left(\text { gdest }_{\mathrm{i}}-\mathrm{s}_{\mathrm{i}}^{\mathrm{k}}\right)
\end{aligned}
$$

Where:

pbest $=$ The particle best position of agent $\mathrm{i}$

gbest $=$ The global particle best position of the group

$\mathrm{C}_{\mathrm{j}}=$ The Correction factor

$\mathrm{w} \quad=$ The weighting function

$v_{i}^{k}=$ The velocity of agent $\mathrm{i}$ at iteration $\mathrm{k}$

rand $=$ Rrandom number between $(0$ and 1$)$ and

$\mathrm{s}_{\mathrm{i}}^{\mathrm{k}}=$ The current position of agent $\mathrm{i}$ at iteration $\mathrm{k}$

The function of the following weighting is usually used in Eq. 7 :

$$
\mathrm{W}=\mathrm{w}_{\max }-\frac{\mathrm{w}_{\max }-\mathrm{w}_{\min }}{\mathrm{iter}_{\max }} \times \text { iter }
$$

Where:

$\mathrm{w}_{\min }=$ The initial weight

$\mathrm{w}_{\max }=$ The final weight itermax is the maximum iteration number and iter is the current iteration number

Using the Eq. 8, a certain speed can be calculated gradually approaching the pbest and gbest.

$$
\mathrm{S}_{\mathrm{i}}^{\mathrm{k}+1}=\mathrm{S}_{\mathrm{i}}^{\mathrm{k}}+\mathrm{V}_{\mathrm{i}}^{\mathrm{k}+1}
$$

Implementation of PSO-PID for BLDC motor: Position evaluation is performed through a fitness function that returns the optimal solution.

Number of particles: The number of particles is assigned to 100 , the purpose is to make a large number of individual elements to better investigate and converge on the optimal PID gain. Robinson and Rahmat-Samii (2004) Carlisle and Dozier (2001) studies show that more particles give an improved study for optimal values compared to the number of particles 20 or 30 . A trade-off between a higher numbers is that higher values take more time to compute than 20 or 30 particles.

PID search space: To find optimal values for the proportional integral and derivative elements. The PID values result from auto-tuning ressulting in PID values. The search space in which the particles worked was set to
50,10 and 450 to provide an effective window to perform a search that would be similar to the PID values found configuration method. The search space also set the boundaries by which the fitness function should be evaluated.

Fitness function: pbest same as gbest random value initially assigned in the search space. For each iteration, the pbest and gbest values are compare with the current position. If the current position has a better value than the current pbest/gbest value, the fitness function returns the value used to calculate the new velocity and the new value replaces the old pbest/gbest value.

Number of trials: The number of tests was established in 50 iterations for each particle. This number has been set to give each particle the ability to successfully find the optimal PID values through multiple trials.

Inertia weight (0.9-0.01): Robinson and Rahmat-Samii (2004) Carlisle and Dozier (2001) was suggested that the internal weight were originally set to 0.9 to provide a global search that is less affected by pbest and gbest. As the number of iterations increases to 50 , the internal weight decreases to 0.01 , leading to the concentrated area which put more emphasis on the activities of pbest and gbest.

Values $\mathbf{C}_{1}$ and $\mathbf{C}_{2}$ : The social factors of $C_{1}$ and $C_{2}$ determine the degree of influence of pbest/gbest on the particle velocity. $\mathrm{C}_{1}$ is set to 2 and $\mathrm{C}_{2}$ is set to 2 , so, more emphasis will be placed on gbest.

Velocity: In order to calculate the speed, we need to evaluate the fitness function of pbest and gbest. In the equation the rand $(\bullet)$ element provides the effect of natural behavior sensation natural (Eq. 6):

Movement: The particle movement is accomplished by adding a new velocity to the current position (Eq. 8) (Robinson and Rahmat-Samii 2004; Carlisle and Dozier 2001).

\section{RESULTS AND DISCUSSION}

This study illustrates the optimization of a conventional PID that uses particle swarm for a controlled closed circuit motor. Figure 3 shows the Simulink Model for optimal control for the BLDC motor. In addition, the components of the motor model are shown in Fig. 4. Where you can monitor the performance of the controller 


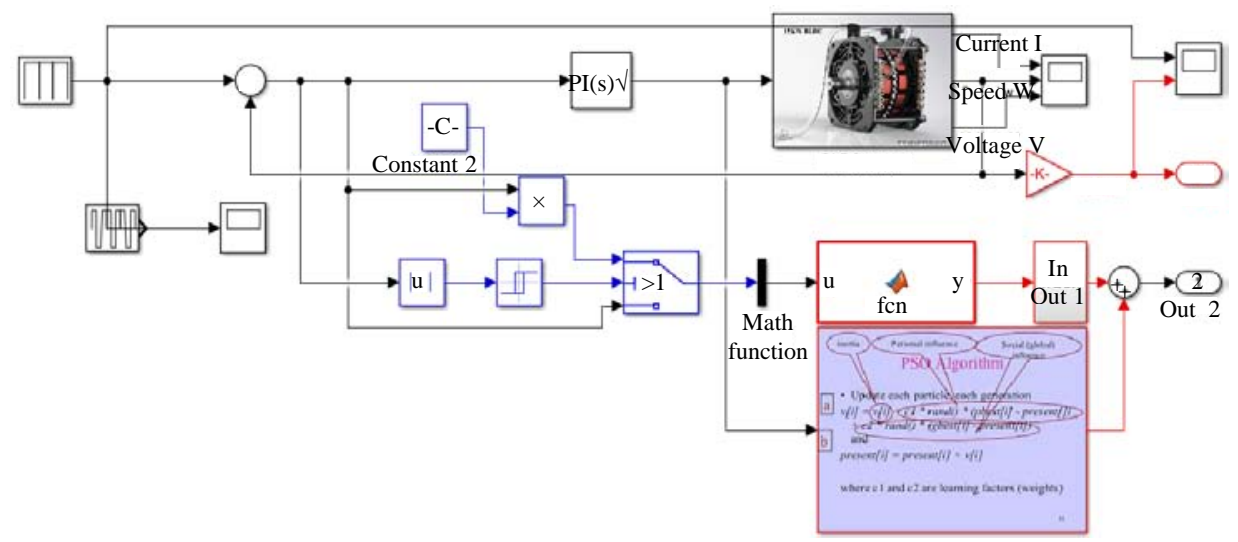

Fig. 3: Simulink Model of PID-PSO controller; Partical swarm ptimization for PID tuning of BLDC motor

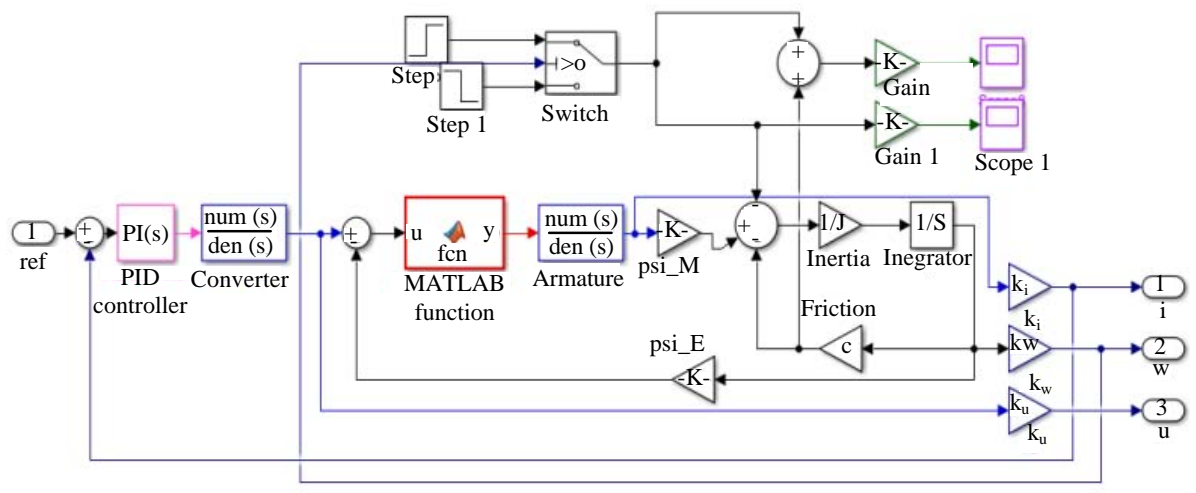

Fig. 4: Components of the BLDC motor model

Table 1: Parameters of the motor

\begin{tabular}{lcl}
\hline Parameters & Symbols & \multicolumn{1}{c}{ Values } \\
\hline Power & $\mathrm{P}_{\mathrm{n}}$ & $4 \mathrm{e} 3 \mathrm{~W}$ \\
Voltage & $\mathrm{U}_{\mathrm{n}}$ & $280 \mathrm{~V}$ \\
Current & $\mathrm{I}_{\mathrm{n}}$ & $17.5 \mathrm{~A}$ \\
Angular velocity & $\mathrm{w}_{\mathrm{n}}$ & $1980 \mathrm{rad} / \mathrm{sec}$ \\
Armatures resistance & & \\
& $\mathrm{R}_{\mathrm{n}}$ & $1.69 \Omega$ \\
Armature inductance & $\mathrm{L}_{\mathrm{n}}$ & $6.6 \mathrm{e}-3 \mathrm{H}$ \\
Rotor inertia & $\mathrm{J}$ & $0.02 \times 2 \mathrm{~kg} \cdot \mathrm{m}^{2}$ \\
Torque & $\mathrm{T}_{\mathrm{n}}$ & $19.3 \mathrm{~N} \cdot \mathrm{m}$ \\
\hline
\end{tabular}

Table 2: Parameter for PSO

\begin{tabular}{lcc}
\hline Parameters & Symbol & Values \\
\hline Number of particles & $\mathrm{n}$ & 120 \\
Cognitive factor & $\mathrm{C}_{1}$ & 2.05 \\
Exploration factor & $\mathrm{C}_{2}$ & 2.05 \\
\hline
\end{tabular}

PSO at different operating conditions. The motor settles at a set speed quickly with less overshoot than the conventional controller is shown below. In addition, Fig. 8 shows the velocity versus time graph for the conventional and inspired optimization method (PSO). The motor is calculated using the specific values as shown in Table 1 (Lee et al., 2018).
In this study, a time domain criterion is used for evaluating the PID controller. The performance criterion $\mathrm{F}$ inludes the overshoot $\mathrm{Mp}$, rise time $\mathrm{t}_{\mathrm{r}}$, settling time $\mathrm{t}_{\mathrm{s}}$ and steady-state error $\mathrm{E}_{\mathrm{ss}}$; It is determined as Eq. 9:

$$
F=\left(1-\exp ^{(-0.5)}\right) \times\left(M_{p}+E_{s s}\right)+\exp ^{(-0.5)} \times\left(t_{s}-t_{r}\right)
$$

Calculations are performed using the specified PSO parameters as shown in Table 2; Fig. 5 and 6 (Lee et al., 2018; Kumar and Chaursiya, 2017; Ridwan et al., 2017). Figure 7 shows the convergence graph in the PSO method. Conventional PID controllers have poor performance due to the wrong selection of PID parameters using manual settings. The response of a controller is made between the simulation time and the speed of the motor. The controller swarm optimisation reduces the settling time of the PID controller by $50 \%$ and eliminates the overshoot and undershoot values.

The results of the PSO simulation provide the best performance over the conventional device of the PID control for the speed of the motor BLDC at different set-point values. The optimal PID controller is shown in Fig. 8 and Table 3. 


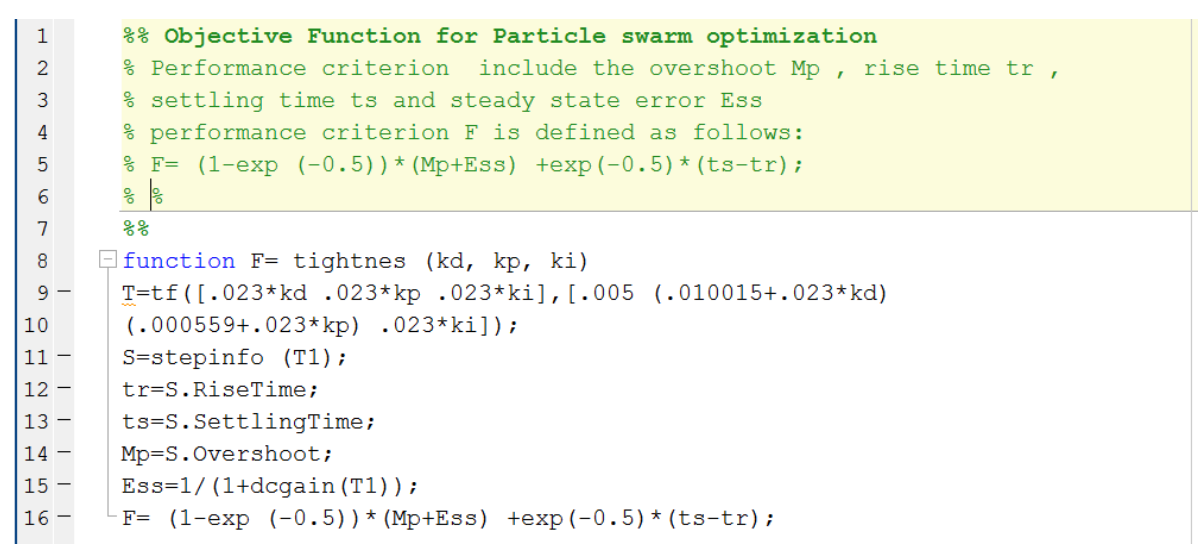

Fig. 5: Objective function for particle swarm optimization
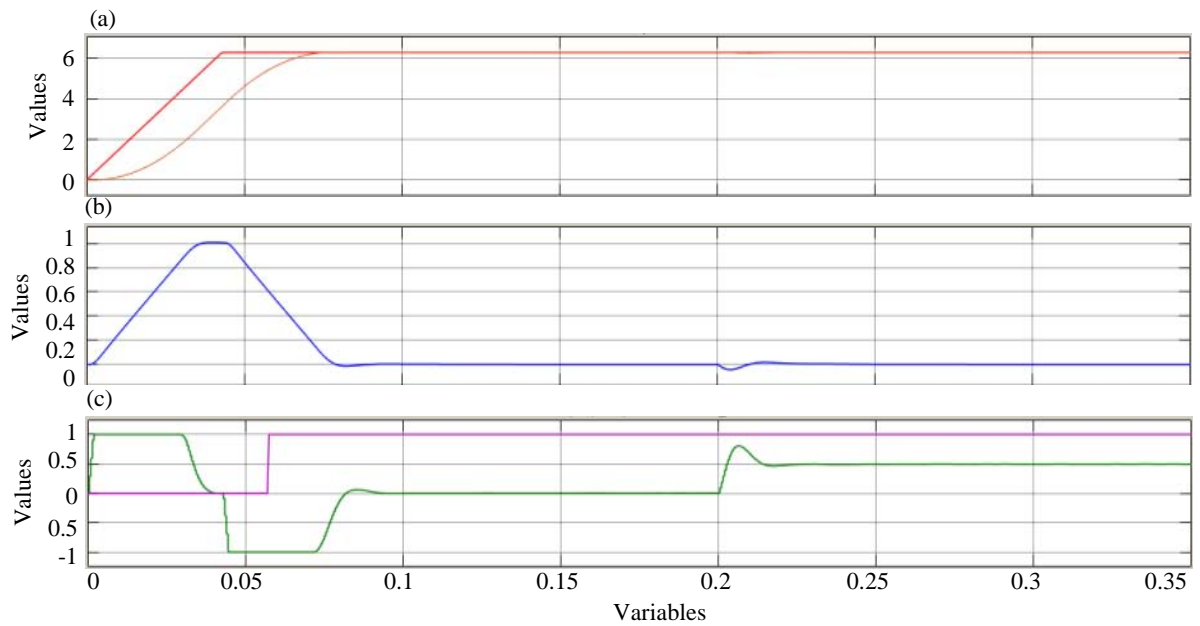

Fig. 6: Simulate position and torque (norm) for the BLDC motor: a) O/P response; b) Position control and c) Torque (norm), fitness function-1

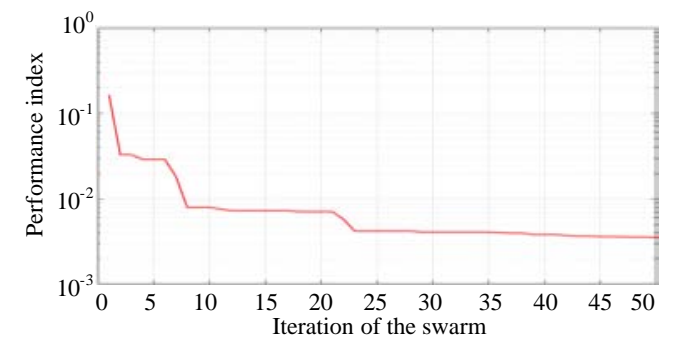

Fig. 7: Fitness function convergence graph PSO controller

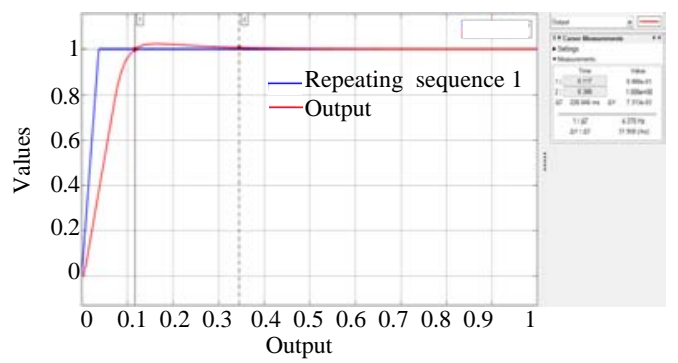

Fig. 8: Speed versus time plot for PID tuned with PSO
Table 3: Summary of simulation parameters

\begin{tabular}{lc}
\hline Variable & Values \\
\hline Elapsed time & $12 \mathrm{~min}$ \\
Swarm diversity & 0.49424 \\
\hline
\end{tabular}

\section{CONCLUSION}

This study proposes a new and improved way to determine parameters for traditional PID control unit by using the optimal PSO method. This may be the best way to improve the performance results of the system and show that the proposed controller can update the PID parameters effectively.

\section{ACKNOWLEDGEMENT}

We would like to express our deep gratitude to our dear advisers, Dr. Shaorong Wang, Janan Al-Hajji for motivating and inspiring us as we completed this research work. 


\section{REFERENCES}

Carlisle, A. and G. Dozier, 2001. An off-the-shelf PSO. Proceeding of the Workshop on Particle Swarm Optimization, April 6-7, 2001, Purdue School of Engineering and Technology, Indianapolis, IN., USA., pp: 1-6.

Chen, S.C. and C.Y. Kuo, 2017. Design and implement of the recurrent radial basis function neural network control for brushless DC motor. Proceedings of the 2017 International Conference on Applied System Innovation (ICASI), May 13-17, 2017, IEEE, Sapporo, Japan, ISBN:978-1-5090-4898-4, pp: 562-565.

Da Cunha Reis, M.R., W.R.H. de Araujo, W.P. Calixto and A.J. Alves, 2015. Analysis of switched reluctance motor efficiency under different speed control strategies. Proceedings of the 2015 International CHILEAN Conference on Electrical, Electronics Engineering, Information and Communication Technologies (CHILECON), October 28-30, 2015, IEEE, Santiago, Chile, ISBN:978-1-4673-8756-9, pp: 467-472.

Das, U., P.K. Biswas and S. Debnath, 2017. Modeling and simulation of open loop model of brush less DC motor by using MATLAB based software. Intl. J. Electron. Electr. Comput. Syst., 6: 1-7.

Gowthaman, E., V. Vinodhini, M.Y. Hussain, S.K. Dhinakaran and T. Sabarinathan, 2017. Speed control of permanent magnet brushless DC motor using hybrid fuzzy proportional plus integral plus derivative controller. Energy Proc., 117: $1101-1108$.

Ibrahim, H.E.A., F.N. Hassan and A.O. Shomer, 2014. Optimal PID control of a brushless DC motor using $\mathrm{PSO}$ and BF techniques. Ain Shams Eng. J., 5: 391-398.

Kamalapathi, K., P. Suresh and P.V.V. Prasad, 2017. Implementation of $\mathrm{PFC}$ converter based digital speed controller for BLDC motor drives. Intl. J. Eng. Res. Sci. Tech., 1: 23-32.

Kavitha, D., A. Amudha and S. Divya-priya, 2017. Design of a controller for regenerative braking using BLDC motor applicable for electric vehicle. Intl. J. Electron. Electr. Comput. Syst., 6: 245-252.

Kim, T., H.W. Lee and M. Ehsani, 2007. Position sensorless brushless DC motor/generator drives: Review and future trends. IET. Electr. Power Appl., 1: 557-564.

Kumar, B., S.K. Swain and N. Neogi, 2017. Controller design for closed loop speed control of BLDC motor. Intl. J. Electr. Eng. Inf., 9: 146-160.
Kumar, M. and K. Chaursiya, 2017. Position control of brushless DC motor using harmony search algorithm optimization technique. Proceedings of the 2017 International Conference on Electronics, Communication and Aerospace Technology (ICECA) Vol. 1, April 20-22, 2017, IEEE, Coimbatore, India, ISBN:978-1-5090-5685-9, pp: 754-757.

Lee, J.H., J.Y. Song, D.W. Kim, J.W. Kim and Y.J. Kim et al., 2018. Particle swarm optimization algorithm with intelligent particle number control for optimal design of electric machines. IEEE. Trans. Ind. Electron., 65: 1791-1798.

Nasri, M., H. Nezamabadi-Pour and M. Maghfoori, 2007. A PSO-based optimum design of PID controller for a linear brushless DC motor. World Acad. Sci. Eng. Technol., 26: 211-215.

Ou, C. and W. Lin, 2006. Comparison between PSO and GA for parameters optimization of PID controller. Proceedings of the 2006 IEEE International Conference on Mechatronics and Automation, June 25-28, 2006, IEEE, Luoyang, Henan, China, ISBN:14244-0465-7, pp: 2471-2475.

Rajkumar, M.V., G. Ranjhitha, M. Pradeep and R. Sathishkumar, 2017. Fuzzy based speed control of brushless DC motor fed electric vehicle. Intl. J. Innovative Stud. Sci. Eng. Technol., 3: 12-17.

Ridwan, M., D.C. Riawan and H. Suryoatmojo, 2017. Particle swarm optimization-based BLDC motor speed controller with response speed consideration. Proceedings of the 2017 International Seminar on Intelligent Technology and its Applications (ISITIA), August 28-29, 2017, IEEE, Surabaya, Indonesia, ISBN:978-1-5386-2709-9, pp: 193-198.

Robinson, J. and Y. Rahmat-Samii, 2004. Particle swarm optimization in electromagnetics. IEEE Trans. Antennas Propagation, 52: 397-407.

Singh, P.K., B. Singh, V. Bist, K. Al-Haddad and A. Chandra, 2018. BLDC motor drive based on bridgeless landsman $\mathrm{PFC}$ converter with single sensor and reduced stress on power devices. IEEE. Trans. Ind. Appl., 54: 625-635.

Viji, V. and S. Arumugam, 2017. A speed controlled PFC modified bridgeless converter based BLDC motor drive with optimal PID algorithm. Asian J. Eng. Technol. Appl., 1: 1-12.

Zhang, S. and Y. Wang, 2016. The simulation of BLDC motor speed control based-optimized fuzzy PID algorithm. Proceedings of the 2016 IEEE International Conference on Mechatronics and Automation (ICMA), August 7-10, 2016, IEEE, Harbin, China, ISBN:978-1-5090-2397-4, pp: 287-292. 